\title{
A TRAJETÓRIA DA LUTA PELA LEGALIZAÇÃO DA AUDIODESCRIÇÃO NO BRASIL: ENTRE A LEGALIDADE E A LEGITIMIDADE
}

\author{
The trajectory of the fight for the legalization of the audiodescrição in Brazil: between \\ legality and legitimacy
}

\section{La trayectoria de la lucha por la legalización de la audiodescripción en Brasil: entre la legalidad y la legitimidad}

Eliamar Godoi*

Késia Pontes de Almeida**

\begin{abstract}
Resumo
Este trabalho trata sobre as origens do movimento de pessoas com deficiência no Brasil e trouxe o tema da implantação da audiodescrição nos veículos de informação brasileiros, cujos dados recolhidos trazem uma reflexão sobre a relação entre estado e sociedade civil por direitos. A partir de uma trajetória traçada sobre o processo de implantação da audiodescrição nos meios de comunicação brasileiros, o texto reflete as discussões e luta demonstrados por ações desenvolvidas por três grupos diferentes que participaram dos debates sobre a implantação deste recurso, quais sejam: pessoas cegas e baixa visão e suas entidades representativas, empresas e associação de defesa dos interesses de quem trabalha com telecomunicação, e, instituições governamentais, incluindo alguns pontos garantidos pela lei brasileira de inclusão. O resultado do trabalho evidenciou a necessidade de mais pesquisas envolvendo a audiodescrição, as necessidades de acessibilidade das pessoas com deficiência visual e, também, a testagem do mecanismo em termos de eficiência e alcance. O resultado evidenciou ainda a grande necessidade de investimento em formação e capacitação de profissionais para atuarem na área a partir da criação de cursos de formação e capacitação de profissionais nos diferentes níveis.
\end{abstract}

PALAVRAS-CHAVE: Audiodescrição. Pessoa com Deficiência Visual. Direitos. Desenho Universal.

\begin{abstract}
This paper deals with the origins of the movement of people with disabilities in Brazil and has introduced the topic of the implementation of audiodescription in Brazilian information channel, whose data reflect a reflection on the relationship between state and civil society by rights. Based on a trajectory traced on the process of implementation of audiodescription in the Brazilian media, the text reflects the discussions and fight demonstrated by actions developed by three different groups that participated in the debates about the implementation of this resource, namely: blind and low vision and its representative entities, companies and associations to defend the interests of those who work with
\end{abstract}

\footnotetext{
* Doutora em Estudos Linguísticos. Docente do Instituto de Letras e Linguística - ILEEL e do Programa de PósGraduação em Estudos Linguísticos - PPGEL da Universidade Federal de Uberlândia - UFU. Coordenadora do CEPAE, núcleo de acessibilidade da Universidade Federal de Uberlândia-UFU. Líder do Grupo de Pesquisas em Estudos da Linguagem, Libras, Educação Especial e a Distância e Tecnologias - GPELET. Email: eliamarufu@gmail.com. Orcid: https://orcid.org/0000-0001-9306-1379.

** Doutora em História. Servidora lotada no CEPAE, núcleo de acessibilidade da Universidade Federal de Uberlândia-UFU. Pesquisadora do Grupo de Pesquisas em Estudos da Linguagem, Libras, Educação Especial e a Distância e Tecnologias - GPELET. Email: kesiahistoria@gmail.com. Orcid: https://orcid.org/0000-0002-90283766.
} 
telecommunications, and governmental institutions, including some points guaranteed by the Brazilian law of inclusion. The result of the work evidenced the need for more research involving audiodescription, the accessibility needs of people with visual impairment, and also the testing of the mechanism in terms of efficiency and scope. The result also highlighted the great need for investment in training and qualification of professionals to work in the area through the creation of training courses and training of professionals at different levels.

KEYWORDS: Audiodescription. Person With Visual Impairment. Rights. Universal Design.

\section{Resumen}

Este trabajo trata sobre los orígenes del movimiento de personas con discapacidad en Brasil y trajo el tema de la implantación de la audiodescripción en los vehículos de información brasileños, cuyos datos recogidos traen una reflexión sobre la relación entre estado y sociedad civil por derechos. A partir de una trayectoria trazada sobre el proceso de implantación de la audiodescripción en los medios de comunicación brasileños, el texto refleja las discusiones y lucha demostradas por acciones desarrolladas por tres grupos diferentes que participaron de los debates sobre la implantación de este recurso, que son: personas ciegas y de baja visión y sus entidades representativas, empresas y asociación de defensa de los intereses de quienes trabajan con telecomunicación, y, instituciones gubernamentales, incluyendo algunos puntos garantizados por la ley brasileña de inclusión. El resultado del trabajo evidenció la necesidad de más investigaciones que involucra la audiodescripción, las necesidades de accesibilidad de las personas con discapacidad visual y, también, la prueba del mecanismo en términos de eficiencia y alcance. El resultado evidenció además la gran necesidad de inversión en formación y capacitación de profesionales para actuar en el área a partir de la creación de cursos de formación y capacitación de profesionales en los diferentes niveles.

PALABRAS ClAVE: Audiodescripción. Persona con Discapacidad Visual. Derechos. Diseño Universal.

\section{Aspectos introdutórios: conceitos, direitos e legislação}

De modo geral, a audiodescrição é um recurso de acessibilidade que amplia a compreensão e a participação das pessoas com deficiência visual ao ter contato com informações não verbais dos meios de comunicação. Esse recurso consiste na tradução das imagens em palavras, por meio de uma descrição objetiva, que em conjunto com as falas originais, permite à pessoa cega e/ou a pessoa com deficiência visual a compreensão integral do conteúdo. Na televisão brasileira a audiodescrição é obrigatória, desde 2011, sendo que os canais são obrigados a exibir no mínimo seis horas por semana de programação com esse recurso. (TV BRASIL ${ }^{1}, 2016$ ).

Para as pessoas com deficiência, a audiodescrição é uma tecnologia assistiva, um recurso de acessibilidade que permite ouvir o que não pode ser visto, compreender o que não pode ser compreendido sem o uso da visão. Motta e Romeu Filho (2010) resumem que a audiodescrição se constitui enquanto uma atividade de mediação linguística, uma modalidade de tradução intersemiótica, que transforma o visual em verbal, abrindo possibilidades maiores de acesso à cultura e à informação, contribuindo para a inclusão cultural, social e escolar.

O símbolo internacional da audiodescrição - AD))) - é composto pelas letras A e D, à direita da letra $\mathrm{D}$ três sinais de parênteses lembram ondas sonoras se propagando. De acordo

1 Disponível em: http://www.ebc.com.br/cidadania/2015/08/acessibilidade-entenda-o-que-e-audiodescricao Acesso em: 21 mai. 2018.

Educação e Fronteiras On-Line, Dourados/MS, v.10, n.28, p.22-33, jan./abr. 2020 
com o Blog da Audiodescrição ${ }^{2}$, essa tecnologia assistiva é destinada e imprescindível às pessoas cegas ou com baixa visão, no entanto esse Blog ainda esclarece e ressalta que a audiodescrição também favorece idosos, disléxicos e pessoas com deficiência intelectual, se estendendo inclusive a compreensão de informações imagéticas para todas as pessoas que, por algum motivo, estão impedidas de ver as imagens, como programas de rádio, por exemplo.

No Brasil a definição do conceito de audiodescrição passou a existir legalmente por meio da Portaria $\mathrm{n}^{\mathbf{o}}$ 310, de 27 de junho de 2006, diferenciando da dublagem. Esta Portaria diferencia a audiodescrição da dublagem, já amplamente adotada em vídeos, caracterizada pela tradução de programas, filmes, documentários falados em língua estrangeira, através da substituição da locução original por falas em língua nacional. A dublagem deve ser feita de forma sincronizada respeitando o movimento dos lábios dos personagens em cena, a fim de transmitir ao expectador, incapaz de acompanhar a legenda a fidelidade das imagens e do conteúdo apresentado. (ALMEIDA, 2011).

De acordo com esse Blog, as primeiras iniciativas de implantação da audiodescrição aconteceram em peças de teatro, logo em seguida o cinema, pouco mais tarde a televisão e desde 2013 a profissão de audiodescritor está registrada na CBO - Classificação Brasileira de Ocupações do Ministério do Trabalho, no entanto, ainda falta a regulamentação do exercício dessa profissão. Existem pelo menos três perfís de especialistas na produção da audiodescrição, a saber: audiodescritor roteirista, audiodescritor narrador e audiodescritor consultor. O Blog da Audiodescrição informa ainda que já existem diversas empresas especializadas em audiodescrição em todas as regiões do país, mas a grande maioria dos profissionais ainda trabalham como autônomos.

Nesse contexto, assumimos como objetivo para esse estudo o de apresentar a trajetória da luta pela legalização da audiodescrição no Brasil, a partir de aspectos da legislação que garantem o direito à acessibilidade das pessoas com deficiência visual. A busca é por compreender como se deram as conquistas deste seguimento e pensar como o arcabouço legal se relaciona com as pessoas da sociedade civil e suas representatividades, além disso, apontar e difundir a audiodescrição enquanto um recurso de acessibilidade que amplia o entendimento das pessoas com deficiência visual em diversos campos.

A pesquisa se mostrou do tipo qualitativo de cunho teórico e descritivo, sendo que as obras como as de Motta e Romeu Filho (2010), Franco e Silva (2010) e Almeida (2011), além das Leis 10.098/00, 13.146/15 e Decreto 5.296/04, entre outros, fundamentaram nossa discussão. Fazendo um retrospecto a respeito dos encaminhamentos legais do processo de implementação de políticas de acessibilidade, em 19 de dezembro de 2000 foi sancionada a Lei 10.098 que estabeleceu normas gerais e critérios básicos para a promoção da acessibilidade das pessoas com deficiência ou com mobilidade reduzida aos espaços físicos, aos meios de transporte e à informação. Neste sentido, nos interessa os itens que garantem o acesso à informação pelas pessoas com deficiência através da promoção de meios de comunicação adaptados às necessidades destas pessoas, importando aqui as diretrizes voltadas às pessoas com deficiência visual. Para tal, analisaremos alguns itens que tratam desse assunto. (BRASIL, Lei 10.098/00).

No contexto da formação, Franco e Silva (2010) esclarecem que três modelos de formação em audiodescrição têm sido utilizados, quais sejam: o treinamento através de cursos de curta duração ministrados por audiodescritores com experiência de mercado; o treinamento em serviço promovido por empresas que trabalham com audiodescrição; e a formação

\footnotetext{
${ }^{2}$ Disponível em: http://www.blogdaaudiodescricao.com.br/audiodescricao Acesso em: 21 mai. 2018.
} 
acadêmica, em geral na forma de módulos em cursos de mestrado em Tradução Audiovisual, ou cursos certificados em nível de extensão.

Para essas autoras, o movimento por uma maior normatização e profissionalização na área tem crescido bastante, além disso a necessidade de uma formação sólida para que se possa projetar, de forma eficaz, o resultado da percepção visual sobre o discurso tem crescido vertiginosamente, o que pode gerar significativo impacto na projeção da formação universitária, a qual pode eventualmente vir a ser privilegiada. (FRANCO; SILVA, 2010).

A seguir, traçamos um histórico das políticas de inclusão brasileira com ênfase na acessibilidade da pessoa com deficiência visual, e, além desses aspectos introdutórios até aqui apresentados, trazemos leituras de documentos legais relevantes e conceitos descrevendo como se estabeleceram as questões envolvendo a ANATEL- Agência Nacional de Telecomunicações e cumprimento das determinações legais sobre a implantação da audiodescrição nos meios de comunicação de massa.

\section{Documentos legais e ações: para a implantação de uma política de inclusão}

De acordo com Franco e Silva (2010, p. 20) a audiodescrição "nasceu em meados da década de 70 nos Estados Unidos, a partir das ideias desenvolvidas por Gregory Frazier em sua dissertação de mestrado". Apesar de ter sua origem no contexto acadêmico, a audiodescrição logo adquiriu um caráter mais prático-técnico e utilitário. Franco e Silva (2010, p. 19) ainda esclarecem que a audiodescrição sendo uma realidade em países da Europa e nos Estados Unidos, "vem paulatinamente ganhando maior visibilidade e projeção também em outros locais, à medida que o direito da pessoa com deficiência visual à informação e ao lazer é reconhecido e garantido".

Sobre a relevância das pesquisas sobre audiodescrição, de acordo com Franco e Silva (2010), as pesquisas procuram, a princípio, traçar um perfil da população com deficiência visual e seus hábitos televisivos, estabelecer se a audiodescrição seria um recurso apreciado por seu público alvo, e determinar se o seu uso contribuiria para que esse público compreendesse materiais audiovisuais mais facilmente. As autoras asseveram que essas pesquisas foram de fundamental importância, pois, além de tornarem mais clara a relação das pessoas com deficiência visual com a televisão e o vídeo, suas necessidades e preferências, elas também demonstraram a validade da audiodescrição para seus usuários.

No Brasil, para acompanhar a aplicação das políticas de inclusão, o poder público é designado como o agente que deve promover políticas de fomento para a remoção de barreiras por meio da produção de espaços, produtos e serviços que tivessem recursos de acessibilidade, dentre eles a audiodescrição (BRASIL, Lei 10.098/00). O poder público também assume a responsabilidade de capacitar profissionais a fim de apoiar as pessoas com deficiência sensorial no processo de comunicação com o meio exterior, temos como exemplo: intérpretes de libras, guias intérpretes, guias, pessoas fluentes na escrita braile, e no caso da audiodescrição, indivíduos que saibam aplicar corretamente as técnicas para implementá-las. Além disso, o Estado passou a se responsabilizar pela remoção das barreiras que impeçam a locomoção, o transporte e o acesso à comunicação pelas pessoas com deficiência tanto no âmbito arquitetônico quanto no campo das comunicações através da disponibilização de ajudas técnicas adequadas a cada ambiente.

No ano de 2005, de acordo com Almeida (2011), a Associação Brasileira de Normas Técnicas - ABNT- redigiu a primeira norma brasileira, a qual regulamentou a implementação 
dos recursos de acessibilidade aos meios de comunicação de massa e estabeleceu as regras voltadas à audiodescrição, nos itens $6.1,6.2$ e 6.3 as quais podemos citar: descrição das informações que não podiam ser apreendidas com a visão com precisão, sem monotonia ou exageros; as descrições deviam ser compatíveis com o tipo de programa adotando um texto mais objetivo em conteúdos adultos e uma fala mais poética para os infantis; a fala deveria ser diferenciada daquela adotada nos programas e as descrições deveriam ser feitas utilizando as pausas entre as falas originais.

Através do Art. 19 da Lei 1098, a ABERT contestou o artigo 53 do Decreto 5.296 alegando que o prazo estabelecido pela ANATEL não poderia ser cumprido pelo fato de a audiodescrição não ser contemplada na referida lei.

No documento de réplica ao da ABERT a ANATEL afirmou que os argumentos do ofício $\mathrm{n}^{\circ} 90$ foram elaborados de forma descontextualizada, isolando apenas uma parte da lei e do decreto. Também chama atenção para o termo deficiência sensorial, que inclui, além dos surdos, os cegos. Portanto, o decreto 5.296 regulamentou de forma legal a lei 10.098, pois específica os recursos necessários à acessibilidade voltada a cada tipo de deficiência sensorial. (ALMEIDA, 2011, p. 82)

$\mathrm{Na}$ nova redação destes artigos além de incluir os recursos de acessibilidade aos meios de comunicação pelas pessoas com deficiência visual e garantir a fabricação de televisores equipados para receber os recursos de acessibilidade, também responsabilizou a CORDE Coordenadoria Nacional para Integração das Pessoas Portadoras de Deficiência, pela ajuda técnica ao Ministério das Comunicações, a fim de que o decreto 5.645 fosse cumprido. Porém, este decreto não contemplou a obrigatoriedade dos canais por assinatura de implementarem os recursos para o acesso às pessoas com deficiência sensorial em seus programas. Isto revela o descompasso entre um poder legislativo moroso e burocrático, que faz valer o pensamento cultural e interesses de alguns grupos sociais, e, uma sociedade civil que precisa lutar para que a legislação seja mais específica e exija que todas as organizações que ofereçam serviços de comunicação de massa, públicas ou privadas, cumpram os direitos e deveres previstos em lei da mesma forma.

Em 27 de junho de 2006, para Almeida (2011), após ouvir e avaliar toda a argumentação técnica, econômica e jurídica apresentadas na consulta e na audiência pública, que tiveram a participação das organizações da sociedade civil, tanto usuários quanto representantes dos meios de comunicação de massa o Ministério das Comunicações publicou a Portaria 310, oficializando a Norma Complementar $n^{\circ} 1$ que estabeleceu o cronograma de implantação e os requisitos técnicos para tornar a programação das TVs abertas, acessíveis às pessoas com deficiência. Pode-se notar que a Norma Complementar No 01/2006, regulamentada pela portaria 301 da ABNT, significou a normatização brasileira para a implementação de recursos de acessibilidade na transmissão e retransmissão dos programas veiculados através de rádio e televisão.

Essa autora ainda esclarece que, a norma ainda estabeleceu prazo de dois anos para que tais normas fossem cumpridas, além de determinar a adoção gradual de recursos acessíveis nos programas transmitidos nestes veículos de comunicação. Desta forma, de acordo com Almeida (2011), as empresas que administravam os meios de comunicação deveriam oferecer, no prazo de dois anos, duas horas de programas acessíveis e, em um prazo de dez anos, adequarem 100\% de sua grade de programação. Tal norma reforça o dever das emissoras de rádio e televisão que possuem permissão para atuar neste ramo, de oferecerem programas acessíveis e este dever passa a ser intransferível, sendo tais emissoras responsáveis diretas pela adaptação dos programas. 
Depois da publicação pelo Ministério das Comunicações da Portaria 310 acima comentada, o então Presidente da República Luís Inácio Lula da Silva assinou o decreto $\mathrm{n}^{\mathrm{o}}$ 5.820, de 29 de junho de 2006, que dispõe sobre a implantação no Brasil do modelo Japonês de transmissão e retransmissão de programas, o SBTVD-T - Sistema Brasileiro de Televisão Digital Terrestre que passou a substituir o sistema analógico de transmissão que era o modelo adotado no país e atualmente passa pelo processo de transição para o sistema digital.

É importante frisar que a Norma Complementar $\mathrm{n}^{\mathbf{0}} 1$, assim como a NBR 15290 expedidas pela $\mathrm{ABNT}$, foram elaboradas com base nos recursos de acessibilidade previstas para o padrão de televisão analógico, visto que, até o momento da publicação das mesmas, não havia definição sobre qual sistema de transmissão o Brasil adotaria como padrão. $\mathrm{O}$ decreto estabeleceu o prazo de 10 anos para que o processo de transição fosse efetivado, bem como garante aos usuários da nova tecnologia o acesso gratuito à informação.

Ao definir o novo sistema de audiodifusão a ser adotado no Brasil, o Ministério das Comunicações não revogou a implantação de recursos de acessibilidade à comunicação através do sistema de transmissão analógica, porém a acessibilidade à informação através do sistema digital, neste momento está indefinida. Mas, em compensação, o decreto deixa claro que as normas que regeriam o novo sistema de transmissão seriam regulamentadas, posteriormente. Além disso, garantiu a interatividade do usuário com a programação, o que nos faz crer que as pessoas com deficiência estão incluídas neste item, pois estes usuários utilizam os recursos interativos para receber e buscar informação. (ALMEIDA, 2011).

Por outro lado, este decreto trouxe entrave ao processo de implantação de dispositivos acessíveis no sistema de transmissão analógico, e criou uma obrigatoriedade ambígua: ao mesmo tempo em que as empresas audiodifusoras teriam que implantar dispositivos acessíveis ao sistema de informação analógico e fazê-la em um período de transição para o sistema digital, o qual, passado o período de transição viria a se tornar o sistema de transmissão de informação padrão do Brasil. Assim, as empresas audiodifusoras se utilizam desta ambiguidade para contestar a acessibilidade nos canais analógicos, descumprindo as legislações anteriores, incluindo tal decreto, cujo texto garantia o pleno funcionamento dos serviços dos canais analógicos mesmo em fase de transição.

Como o projeto a ser elaborado pelas redes audiodifusoras baseava-se no decreto $\mathrm{n}^{\circ}$ 5.820, e este não continha diretriz para a inclusão de dispositivos acessíveis, o movimento das pessoas com deficiência precisou recomeçar sua luta pela acessibilidade na comunicação, baseado nas legislações voltadas à transmissão analógica, a fim de garantir os mesmos direitos para o novo modelo de transmissão e retransmissão. A partir daí a vistoria das instalações das emissoras ficou a cargo do Ministério das Comunicações, porém as permissões seriam concedidas sem os dispositivos de acessibilidade. Assim as normas das leis referentes ao modelo analógico puderam ser facilmente contestadas.

No mês de dezembro, estabeleceu-se um marco nas normas internacionais com foco nas pessoas com deficiência, a publicação da Convenção sobre os Direitos das Pessoas com Deficiência pela Assembleia Geral da Organização das Nações Unidas - ONU, garantindo sua plena participação em todos os âmbitos da sociedade. Já no ano de 2007 , no mês de março, o Presidente da República Luís Inácio Lula da Silva protocolou, na ONU, o depósito da assinatura da Convenção Sobre Direitos das Pessoas com Deficiência. O fato relevante da luta pela implementação da audiodescrição no Brasil foi que o presidente realizou o depósito da assinatura de um protocolo adicional a esta convenção, que submete seus signatários ao monitoramento da ONU para o cumprimento dos princípios da convenção no país. 


\section{Veículos de informação: caminhos e descaminhos para a implantação da audiodescrição}

É possível perceber que, ao justificar a ausência de implantação de dispositivos de acessibilidade aos meios de comunicação e do emprego de recursos humanos para tal, saindo da realidade da maioria da população, a ABERT - Associação Brasileira de Emissoras de Rádio e Televisão - afirma que é impossível oferecer dispositivos de acessibilidade caros a uma população sem condições financeiras para mantê-la. Ao fazer essa afirmação, este órgão viola o princípio básico de acessibilidade para todos, aos veículos de informação, bem como, desconsidera as garantias legais do cumprimento de tais direitos.

De acordo com Almeida (2011), em 26 de maio de 2008, um mês antes do final da carência de dois anos determinada pela Norma Complementar $\mathrm{n}^{\circ}$ 1/2006 para o início das transmissões de programação com os recursos de acessibilidade previstos, a ABERT enviou o ofício 40/2008 ao Ministério das Comunicações oferecendo uma série de motivos para solicitar prorrogação do prazo. O documento alegava impedimentos de ordem legal e uma série de dificuldades técnicas, operacionais e econômicas para a implementação dos recursos de acessibilidade na programação veiculada no Brasil, pelas emissoras afiliadas.

Em 27 de junho de 2008, exatamente no dia em que venceria a carência de 02 anos prevista na Portaria 310, o Ministério das Comunicações publicou a Portaria 403, que suspendeu o recurso da audiodescrição por 30 dias, mantendo a obrigação para os demais recursos de acessibilidade previstos na Norma Complementar $\mathrm{n}^{\mathrm{o}} 1$. Isto fez com que a sociedade civil se mobilizasse a favor deste recurso de acessibilidade. A primeira manifestação ocorreu com a moção da então FEBEC- Federação Brasileira de Entidades de e para cegos em favor da implantação da audiodescrição. Assim, além de reforçar a inconstitucionalidade da medida adotada pelo Ministério das Comunicações, a FEBECFederação Brasileira de Entidades de e para cegos pede o apoio da sociedade política na defesa dos direitos à pessoas cegas e com baixa visão. Outra entidade da sociedade civil a se manifestar foi a também extinta União Brasileira de Cegos, que oficiou ao Ministro das Comunicações manifestando seu repúdio pela publicação da Portaria 403. Estas instituições se fundiram em 2008 formando a Organização Nacional de Cegos do Brasil-ONCB.

O descompasso entre a legalidade estabelecida no Estado e seus resultados no interior da sociedade civil, neste caso baseados na ilegalidade mostrou o conflito e a disparidade dos poderes hegemônicos e contra hegemônicos exercidos, respectivamente, pelo Ministério das Comunicações e pelas Entidades de defesa das pessoas com deficiência visual em nível nacional.

Em 09 de julho de 2008, o Congresso Nacional promulgou o Decreto Legislativo 186 que elevou a Convenção Sobre Direitos das Pessoas com Deficiência a Emenda Constitucional, tornando-se o primeiro tratado internacional a vigorar no Brasil nesta categoria. Ao elevar a Convenção sobre os Direitos das pessoas com Deficiência a status de emenda constitucional, a decisão do Ministério das Comunicações de suspender a obrigatoriedade da implantação da audiodescrição nas transmissões das redes audiodifusoras e televisivas, torna-se definitivamente inconstitucional, apesar deste documento estar sujeito a adequações legislativas e realidade nacional.

Com a manifestação das entidades nacionais representativas das pessoas com deficiência visual, a Procuradoria Geral da República abriu processo administrativo e oficiou ao Ministério das Comunicações, solicitando esclarecimentos. Em 23 de julho de 2008, o Ministério das Comunicações realizou reunião técnica da qual participaram representantes da 
ABERT, representantes da UBC - União Brasileira de Cegos - e alguns profissionais de audiodescrição.

Em 30 de julho de 2008, o Ministério das Comunicações publicou a Portaria 466, restabelecendo a obrigatoriedade de veiculação do recurso da audiodescrição e determinou prazo de 90 dias para o início das transmissões. Em outubro, antes do término do prazo de 90 dias estabelecido na Portaria 466, o Ministério das Comunicações novamente suspendeu a aplicação somente do recurso da audiodescrição, conforme previsto na Portaria 310, para a realização de nova consulta pública com prazo até 30 de janeiro de 2009. Outras entidades ligadas às pessoas com deficiência manifestaram seu descontentamento com as medidas tomadas pelo Ministério da Comunicação em relação ao recurso da audiodescrição. Uma dessas entidades foi a COCAS - Comissão Civil de Acessibilidade de Salvador, em novembro, que emitiu nota pública manifestando seu repúdio à protelação na implementação do recurso da audiodescrição.

Outras instituições que se manifestaram em favor da implantação da audiodescrição foram: o Conselho Nacional dos Centros de Vida Independente e a Federação Brasileira das Associações de Síndrome de Down que ingressaram no Supremo Tribunal Federal com Ação de Arguição de Descumprimento de Preceito Fundamental (ADPF 160) contra a União. No documento, alegaram descumprimento, pelo Ministério das Comunicações, dos prazos estabelecidos no Decreto Federal 5.296/2004, que determinou a este Ministério a responsabilidade pela regulamentação dos artigos referentes à acessibilidade aos meios de comunicação.

Posteriormente, a ONCB aderiu a esta ação, sendo que este recurso ao Supremo Tribunal Federal foi possível, graças à promulgação da Convenção Sobre Direitos das Pessoas com Deficiência da ONU, como emenda da constituição brasileira. Além do reforço à inconstitucionalidade de tal portaria a Organização Nacional de Cegos do Brasil - ONCB informa que tomaria todas as medidas legais possíveis, a fim de garantir o cumprimento dos direitos das pessoas com deficiência visual. Além disso, podemos ver a transversalidade expressa pelo movimento, pois ao se manifestarem contra as decisões do Ministério das comunicações, os Centros de Vida Independente e a Federação Nacional das Associações de Síndrome de Down, bem como a manifestação de gratidão por parte da Organização Nacional de Cegos do Brasil - ONCB mostra como as lutas das pessoas com deficiência, apesar de suas ramificações, não são exclusivas, pelo contrário, ganham força quando as organizações representantes de cada tipo de deficiência se unem em favor da igualdade de direitos.

Em fevereiro de 2009, o Ministério Público Federal, por intermédio da Procuradoria Regional dos Direitos do Cidadão do Distrito Federal também ingressou com Ação Civil Pública contra a União. Neste documento são reveladas estratégias para que os interessados não acessassem o conteúdo da consulta pública, bem como considera desnecessária toda essa burocracia para cumprir um direito específico garantido e conceituado mediante os decretos e portarias já citados, e não apenas mencionado de forma genérica e sem qualquer explicação.

O Ministro das Comunicações Hélio Costa, em maio de 2009, mediante despacho, abriu nova consulta pública para que o Ministério das Comunicações recebesse contribuições a respeito da implementação da audiodescrição, conforme notícia divulgada no site do ministério das comunicações. Para essa nova consulta pública foi disponibilizada, no site deste Ministério, uma série de documentos, a fim de nortear a consulta, instituída pela Portaria 661, que se encerrou em janeiro de 2009. No entanto, esses documentos foram publicados no formato PDF, inacessível aos Leitores de Tela, que são programas específicos para que as pessoas cegas, justamente os maiores interessados na implementação do recurso da audiodescrição, pudessem lê-los através do computador. 
O CONADE - Conselho Nacional de Direitos das Pessoas com Deficiência, em resposta a este desrespeito para com as pessoas cegas e com baixa visão, manifestou-se por ofício ao Ministro das Comunicações, em repúdio à falta de acessibilidade aos documentos publicados no site deste Ministério, os quais seriam analisados e criticados pelos órgãos e segmentos diretamente interessados.

As instituições representativas de outros tipos de deficiência - Conselho Nacional dos Centros de Vida Independente, a Federação Brasileira das Associações de Síndrome de Down, bem como a Organização Nacional de Cegos do Brasil - impetraram Mandado de Segurança contra a União. No documento, solicitam o cancelamento da última consulta pública aberta pelo Ministério das Comunicações, em virtude da falta de acessibilidade aos documentos e, ainda, pelo fato de parte deles se encontrarem em outros idiomas, o que restringia, ainda mais, a participação dos interessados na consulta, em igualdade de condições.

Como não houve nenhuma manifestação por parte do Superior Tribunal de Justiça às reivindicações realizadas no Mandado de Segurança, acima citado até 30 de junho, data que encerrou a consulta pública, as entidades impetrantes da ação produziram um aditamento, agora, solicitando a reabertura da consulta pública ao invés de seu cancelamento, para que as pessoas com deficiência visual pudessem participar. De acordo com Almeida (2011), em decisão liminar, no mês de agosto, o Superior Tribunal de Justiça ordenou ao Ministério das Comunicações a reabertura da consulta pública, no prazo de 45 dias, determinando que todos os documentos publicados no site do Ministério das Comunicações fossem adaptados de modo a permitir sua leitura por pessoas com deficiência visual, bem como a tradução para o português dos documentos publicados em outros idiomas.

\section{CONSIDERAÇÕES FINAIS}

O Ministério das Comunicações tem se mostrado enquanto um órgão da sociedade política contrário à legislação formal, atendendo aos interesses das grandes empresas responsáveis pela comunicação. Essa é a prova mais contundente de que apenas a lei escrita não dá garantias de cumprimento de direitos, e sim, a força que um determinado grupo da sociedade civil consegue exercer sobre os órgãos da sociedade política, fazendo prevalecer sua visão cultural de mundo. Neste sentido, pela lei formal, não precisaria regulamentar quaisquer que fossem os sistemas de transmissão adotados no Brasil, uma vez legalizada a acessibilidade do sistema de transmissão analógico, não necessitaria de novas reformulações para o sistema digital, o que não ocorreu na prática.

A Audiodescrição, faixa narrativa adicional para os cegos e pessoas com deficiência visual que são consumidoras de meios de comunicação visual, onde se incluem a televisão e o cinema, a dança, a ópera e as artes visuais, é um direito das pessoas com deficiência visual, porém sua implementação depende de uma atuação mais ativa e planejada do estado, que pode dirimir vários conflitos e interesses que se sobrepõem as necessidades destes cidadãos.

A necessidade da difusão, formação de pessoal para produzir e implantar essa ação de modo a propiciar acessibilidade, requer investimentos em pesquisas, considerando a novidade tanto da lei quanto da ação. A pesquisa sobre este recurso de acessibilidade pode ajudar a difundi-lo por meio de núcleos estabelecidos em várias universidades, porém a produção de conteúdo com acessibilidade é ainda extremamente baixa no país. Com Franco e Silva (2010) entendemos que a audiodescrição não só aumentaria a compreensão dos programas pelas pessoas com deficiência visual, mas também traria uma série de outros benefícios, no sentido 
em que auxiliaria a aquisição de conhecimentos sobre o mundo visual, especialmente aqueles ligados a normas de interação social (linguagem corporal, estilos de roupa, etc.). Nesse contexto, a audioidescrição tornaria a experiência com a TV mais agradável e educativa; proporcionaria um sentimento de maior independência, igualdade e inclusão; e desobrigaria familiares e amigos da tarefa de descrever os programas. Além disso, a audiodescrição traria ainda o benefício de deixar o público com deficiência visual mais confortável para conversar com pessoas videntes sobre os programas a que assistiam (FRANCO; SILVA, 2010).

A título de contextualização, atualmente, no que se refere a garantia de leis, a audiodescrição está contemplada na Lei 13.146/15, a lei brasileira de inclusão mais recente no país. Em termos da acessibilização dos meios de comunicação, já existe um mínimo de tempo de exibição de programas com acessibilidade garantidos. Os ofícios propõem a extensão do prazo de adaptação das redes de audiodifusão, a regulamentação de uma carga horária mínima de programação adaptada de 8 horas, sendo a acessibilidade ao restante da grade de programação facultativa. Assim, a legenda oculta e a audiodescrição seriam aplicadas apenas ao sistema digital de transmissão, através de regras que deveriam ser estabelecidas pelo Ministério das Comunicações. Ocorre que há questionamentos pelo fato de que essa exibição acessibilizada na TV, por exemplo, só tem acontecido em horários inapropriados ou em programas inexpressivos. Essa acessibilização só tem acontecido, ou seja, essa carga horária só tem sido aplicada no período da madrugada em programas de menor expressão, o que não atende às pessoas com deficiência visual. Percebe-se grande viabilidade para o aumento do número de programas com audiodescrição, visto que esse recurso carece do sinal digital, que já está implantado praticamente em todo pais, favorecendo o processo de implantação.

Entre conquistas e retrocessos o movimento das pessoas com deficiência ainda tem muito o que lutar para garantir o cumprimento desta legislação. Nesse sentido, a luta continua a fim se conseguir acessibilizar toda a programação, aumentando o número de programas com acessibilidade, principalmente na TV aberta. Outra luta que está sendo embrenhada pelas pessoas com deficiência visual e as organizações de apoio é pela formalização das normas técnicas que regem o exercício da profissão do audiodescritor na execução desse serviço e também pela criação e formalização das normas técnicas da implantação da audiodescrição junto aos meios de comunicação.

Outro ponto importante está sendo a busca por formação de profissionais capacitados e por profissionais já formados da área para garantir a qualidade da implantação. Há ainda a luta por desenvolvimento e aprimoramento das pesquisas envolvendo tanto as necessidades das pessoas com deficiência visual, quanto sobre o uso e eficácia do mecanismo da audiodescrição nos veículos de informação, medidos por elas. Entendemos que, na atualidade, a luta deve ser no sentido de propiciar o treinamento de profissionais por meio de cursos de curta duração ministrados por audiodescritores com experiência de mercado; busca pelo treinamento em serviço promovido por empresas que trabalham com audiodescrição, além da busca pela formação acadêmica, ou cursos certificados em nível de extensão e até de graduação.

Enfim, a partir desse estudo, a busca foi por informar os interessados da área sobre trajetória da luta das pessoas com deficiência visual pela implantação da audiodescrição nos Veículos de informação e sobre as demais questões de acessibilidade para a pessoa com deficiência visual, apresentando um material que pode servir de referência para os que buscam conhecer a trajetória da legalização, a própria legislação e um pouco sobre a audiodescrição. A legislação determina a implantação da audiodescrição, que surge como uma grande conquista das pessoas com deficiência visual, no entanto, a luta continua. 


\section{REFERÊNCIAS}

ABERT. Apresentação das considerações a respeito do Ofício $n^{o}$ 40/2008 da ABERT (Associação Brasileira de Emissoras de Rádio e Televisão), datado de 26 de maio de 2008.Disponível em:< http://blogdaaudiodescricao.blogspot.com>. Acesso em 06 de abr. 2011.

ALMEIDA, K. P. O Direito das Pessoas com Deficiência Visual à informação: a Luta no Âmbito das Sociedades CivillPolítica pela Audiodescrição no Brasil. 2011. 106 f. Monografia (Especialização) - Curso de História, Instituto de História, Universidade Federal de Uberlândia, Uberlândia, 2011.

BRASIL. AÇÃO CIVIL PUBLICA DO MINISTÉRIO PUBLICO. 2009. BRASIL. Audiodescrição: Portaria 985 do Ministério das Comunicações. PORTARIA n 985 , de 26 de novembro de 2009.

BRASIL. Decreto Legislativo $N^{\circ} 186,2008$.

BRASIL. Lei $n^{\circ}$ 10.098, de 19 de dezembro de 2000.

BRASIL. MINISTÉRIO PÚBLICO FEDERAL. PROCURADORIA FEDERAL DOS DIREITOS DO CIDADÃO. Ata da reunião com Agência Nacional de Telecomunicações, Ministério das Comunicações e Coordenadoria Nacional para a Integração da Pessoa Portadora de Deficiência. In: MINISTÉRIO PÚBLICO FEDERAL. PROCURADORIA FEDERAL DOS DIREITOS DO CIDADÃO. Brasília, 2004.

BRASIL. NORMA BRASILEIRA. Acessibilidade em comunicação na Televisão. ABNT NBR15290. 2005. p. 10.

BRASIL. Ofício ABERT 90/2005 Novembro de 2005.

BRASIL. PORTARIA N $N^{\circ}$ 310, DE 27 DE JUNHO DE 2006.

BRASIL. SDH. Secretaria de Direitos Humanos. "História do Movimento Político das Pessoas com Deficiência no Brasil". Brasília, 2010. 480 p.

BRASIL. Senado Federal. Constituição da República Federativa do Brasil. Brasília, 1988.

BRASIL. Decreto $n^{o} 5.296$ de 2 de dezembro de 2004. OFÍCIO 24/2008. Moção Pública da FEBEC Contra a Suspensão do direito à Audiodescrição. In: Federação Brasileira de Entidades de e para Cegos. Rio de Janeiro, 28 de junho de 2008.

FIGUEIRA, E. Caminhando em silêncio: Uma introdução à trajetória das pessoas com Deficiência na História do Brasil. São Paulo: Giz Editora, 2008.

FIGUEIRA, E. Estado e sociedade. In: MATTOS, Marcelo Badaró (org.). História: pensar \& fazer. Niterói-RJ: LDH/UFF, 1998, p.13-32.

FRANCO, E. P. C.; SILVA, M. C. C. C. Audiodescrição: breve passeio histórico. In: MOTTA, L. M. V. M.; ROMEU FILHO, P. (Orgs.). Audiodescrição: transformando imagens em palavras. São Paulo: Secretaria dos Direitos da Pessoa com Deficiência do Estado de São Paulo, 2010.

MOTTA, L. M. V. M.; ROMEU FILHO, P. (Orgs.). Audiodescrição: transformando imagens em palavras. São Paulo: Secretaria dos Direitos da Pessoa com Deficiência do Estado de São Paulo, 2010.

Educação e Fronteiras On-Line, Dourados/MS, v.10, n.28, p.22-33, jan./abr. 2020 
OFÍCIO N ${ }^{\circ}$ 20/2008/UBC. In: Ofício da UBC ao Ministro das Comunicações. 5 de julho de 2008. BRASILIA.

ONCB. Organização Nacional de Cegos do Brasil. Manifesto em defesa da audiodescrição. São Paulo (2008).

Recebido em: 08/10/2019

Aprovado em: 10/12/2019 